\title{
Dinámicas entre el Estado y la administración pública en el marco de la administración liberal, prestacional y garante*
}

\author{
María Lourdes Ramírez Torrado
}

Resumen: La comprensión del escenario actual de las dinámicas entre Estado y la administración exige tener claridad sobre la relación fluida que han tenido estas instituciones a lo largo del tiempo. Para esto se plantea analizar la evolución de las relaciones entre Estado y administración, así como su impacto en el derecho administrativo. Lo anterior en el marco del modelo de Estado liberal y social. Se llega así, entre otras cuestiones, a la conclusión de que si bien cada modelo de Estado genera una administración con roles diferentes, muchos de los instrumentos propios de los distintos modelos de administración coexisten al tiempo que conviven con unos que se adaptan a los nuevos tiempos.

Palabras clave: administración; administración garante; derecho administrativo; Estado

Fecha de recepción: 5 de abril de 2019 Fecha de evaluación: 4 de octubre de 2019

Fecha de aprobación: 25 de marzo de 2020

Cómo citar: Ramirez Torrado, M. L. (2020). Dinámicas entre Estado y Administración pública en el marco de la administración liberal, prestacional y garante. Prolegómenos, 23(45). https://doi. org/10.18359/prole.4036

* Este artículo de investigación es resultado del proyecto de investigación "Estado/administración en Colombia", investigación financiada por la Universidad del Norte.

Artículo de investigación

a Doctora en Derecho Administrativo, Universidad Carlos III (Madrid, España). Magíster en Derechos Fundamentales, Universidad de Lovaina (Lovaina, Bélgica). Abogada, Universidad del Norte (Barranquilla, Colombia). Profesora investigadora de la División de Derecho, Ciencia Política y Relaciones Internacionales de la Universidad del Norte (Barranquilla, Colombia). Correo electrónico: torradom@uninorte.edu.co. ORCID: orcid.org/0000-0001-6529-0457 


\title{
Dynamics between the State and Public Administration in the Framework of a Liberal, Benefits, and Guaranteeing Administration
}

\begin{abstract}
To understand the current dynamics between state and administration, the fluid relationship between these institutions over time needs to be clear. For this, the article analyzes the evolution of such a relationship, as well as its impact on administrative law in the framework of the liberal and social state model. Among other issues, it concludes that while each state model gives rise to an administration with different roles, many of the instruments of various administration models coexist with each other and with others that adapt to the modern times.
\end{abstract}

Keywords: Administration; guaranteeing administration; administrative law; state.

\section{Dinâmicas entre o Estado e a administração pública no âmbito da administração liberal, prestativa e garantidora}

Resumo: A compreensão do cenário atual das dinâmicas entre o Estado e a administração exige ter clareza sobre a relação fluida que essas instituições vêm tendo. Para isso, propõe-se analisar a evolução das relações entre o Estado e a administração, bem como seu impacto no direito administrativo. Isso no âmbito do modelo de Estado liberal e social. Chega-se, assim, entre outras questões, à conclusão de que, embora cada modelo de Estado gere uma administração com papéis diferentes, muitos dos instrumentos próprios dos diferentes modelos de administração coexistem ao mesmo tempo que convivem com os que são adaptados aos novos tempos.

Palavras-chave: administração; administração garantidora; direito administrativo; Estado. 


\section{Introducción}

La comprensión del escenario actual de las dinámicas entre el Estado y la administración exige tener claridad sobre la relación fluida que han tenido estas instituciones a lo largo del tiempo. Para esto se plantea analizar la evolución de las relaciones entre Estado y administración, así como su impacto en el derecho administrativo. Lo anterior, en el marco del modelo de Estado liberal y social.

De esta manera, se revisa la literatura que se ha ocupado de la cuestión desde distintas aristas, al abordar, en su orden, las relaciones entre sociedad, Estado y administración; a su vez, la administración del orden público en el marco del Estado liberal, la administración prestacional y la administración reguladora en el marco del Estado social y democrático de derecho. Se llega así, entre otras cuestiones, a la conclusión de que si bien cada modelo de Estado genera una administración con roles diferentes a fin de responder a las demandas sociales, muchos de los instrumentos propios de los distintos modelos de administración no se excluyen, sino que se complementan.

\section{A. Relaciones entre sociedad, Estado y administración}

Las relaciones entre sociedad y Estado se han reacomodado de forma continua a causa del replanteamiento de sus roles (Schmidt-Abmann, 2006), de manera que influencian, a su vez, la relaciones Estado/administración.

La adaptación de la administración a las demandas de la sociedad en la que está inmersa obedece a la necesidad de responder a sus tradiciones nacionales, a su escenario económico, social, cultural, e incluso a las condiciones geográficas en las que se desarrolla, pues no se trata de un modelo único de administración pública (Braibant, 2002). Como lo expresa Merkl (2004), "lo mismo que las distintas formas de Estado repercuten en la organización administrativa, las diferencias en las concepciones políticas dominantes, dejan huella, más clara todavía, en ese contenido de la actividad administrativa" (p. 84).
Ese ajuste de la administración a la evolución de las relaciones del Estado y la sociedad se evidencia en la dinámica que describe Muñoz Machado (2011), cuando afirma que no es lo mismo:

un Estado que se abstiene y retrae, potenciando al máximo la posibilidad de que la sociedad asuma la satisfacción de sus necesidades y organizando los mercados [...], que un Estado que, como el del siglo $\mathrm{xx}$, se preocupa de participar activamente. Si el tiempo presente es el del retraimiento y potenciación de la sociedad, las instituciones privadas y las empresas (p. 202).

Así, estas transformaciones que ocurren en las relaciones entre la sociedad, el Estado y la administración tienen repercusiones directas en los objetivos, las instituciones y los instrumentos que le permiten intervenir a la administración, y, por ende, en el contenido y la finalidad del derecho administrativo. Debe, entonces, brindar herramientas para la realización de actuaciones administrativas que permitan concretar los objetivos de un modelo de Estado liberal, prestacional o regulador (Alviar García, 2007). Así, Martín-Retortillo Baquer (2012) expresa que "cambian aspiraciones y necesidades - y el propio nivel de vida-, y por lo mismo se exige adaptar permanentemente los instrumentos jurídicos que, como el derecho administrativo tan vinculados están a la vida en sociedad" (pp. 247-276).

\section{B. Administración del orden público en el marco del Estado liberal}

El Estado liberal está construido sobre la base de la libertad, la propiedad individual, la igualdad y la participación de ciertos sectores en la toma de las decisiones. Para esto se partía de supuestos como, por ejemplo, el imperio de la ley, la división de los poderes públicos, la legalidad de la administración y la declaración de los derechos civiles y políticos. Lo anterior, al ser la intervención del Estado en la vida económica y social bastante exigua, pues era la sociedad misma la que tenía que dar respuesta a las necesidades de la población. Para el contexto español se tiene que lo siguiente: 
a finales del xix y comienzos del siglo $\mathrm{xx}$, la administración de la época es una escasamente profesionalizada, salvo en los ramos concretos servidos por el personal facultativo salido de las escuelas especiales de ingenieros, creadas inicialmente por la propia administración con la finalidad primordial de formar sus propios cuadros [...]. El contexto ideológico de la época tampoco exige más del Estado y de su aparato administrativo, al que veda, incluso, la sanción del protagonismo alguno en el escenario económico (Fernández, 2001, p. 8).

De otra parte, se manifiesta que uno de los rasgos sobresalientes del Estado liberal es la diferencia y la distancia entre sociedad y el Estado, a los que se les consideraba dos órdenes autónomos y distintos. Así, señala García Pelayo (2009):

el Estado era concebido como una organización racional orientada hacia ciertos objetivos y valores y dotada de estructura vertical o jerárquica, es decir, construida primordialmente bajo relaciones de supra y subordinación. Tal racionalidad se expresaba en leyes abstractas, en la división de los poderes como recurso racional para la garantía de libertad y la diversificación e integración del trabajo estatal, y en una organización burocrática de la administración. Sus objetivos y valores eran la garantiza de la libertad, de la convivencia pacífica, de la seguridad, y de la propiedad [...]. La sociedad en cambio, era considerada como una ordenación, es decir como un orden espontaneo dotado de racionalidad, pero no de una racionalidad previamente proyectada, sino de una racionalidad inmanente, que se puede constatar y comprender [...], una racionalidad expresada en leyes económicas y de otra índole, más poderosas que cualquier ley jurídica, y una racionalidad, en fin, no de estructura vertical o jerárquica, sino horizontal y sustentada capitalmente sobre las relaciones competitivas a las que se subordinan las otras clases o tipos de relaciones (García Pelayo, p. 22).

De modo que las relaciones del Estado y la sociedad eran ajenas entre sí; la sociedad se encargaba del desarrollo de las actividades sociales, económicas y de beneficencia, a través de la Iglesia y de particulares (Esteve Pardo, 2016), y el Estado del mantenimiento del orden público. Este escenario conllevó a la colocación "en el centro del sistema a los poderes públicos, culminando la sacralización del Estado, que se sitúa por encima de los ciudadanos" (Linde Paniagua, 2014, p. 51).

La administración tenía "un conjunto de fenomenales potestades y poderes, ante los cuales solo cabía la sumisión por parte de los administrados. Eran tiempos en los que la legalidad administrativa [...] era la guía y el norte de la actuación administrativa" (Rodríguez Arana, p. 97).

En cuanto a las respuestas del derecho administrativo, el derecho francés respondió a este tipo de relaciones del modelo liberal con la distinción de actos de autoridad y actos de gestión, e intentó así responder además a las necesidades de la administración de la sociedad industrial y definir los eventos que se aplican en el derecho administrativo.

De esta manera, se comprende que la administración actúa o bien desplegando su poder (imperium), o bien en la misma condición de los administrados. Sin embargo, este concepto no fue suficiente, pues en todos los casos no es posible diferenciar cuándo el Estado se desprende o no de su autoridad. Ante lo cual aparece, posteriormente, otra tesis, la cual se centra en el puissance publique, convirtiéndose en uno de los intentos de explicar la esencia del derecho administrativo. Linde Paniagua (2014) considera que "la administración está investida de poder público cuando dicta ordenes, establece prohibiciones, cuando ejecuta actos administrativos, cuando desarrolla leyes o las complementa mediante reglamentos" (p. 62). De ese poder de la administración, de acuerdo con el autor citado, se derivan "el privilegio de la acción directa, de la acción ejecutoria, y la instrumentación de la jurisdicción contencioso-administrativa a instancia de la parte perjudicada" (p. 62).

En Alemania, el planteamiento de autores como Gerber, Laband y Jellinek sugiere al Estado como poder de dominación soberano, lo que le permite imponerse de una forma irresistible y someterse a reglas jurídicas (Troconso Reigada, 1999; Muñoz Machado, 2011).

Gerber (1823-1891, profesor de derecho público alemán) trasladó algunas figuras del derecho privado al público, entre ellas la de la personalidad jurídica. De esta manera, se permitió a la administración ser sujeto de derechos y someterlo a la 
legalidad (Esteve Pardo, 2016). Así, el reconocimiento del Estado como persona jurídica (lo cual se toma del derecho civil) se erige en el soporte de la construcción jurídica del derecho público que abarca a los tres poderes (García de Enterria y Fernández, 2006).

Para Paul Laband (1838-1918, profesor de Estrasburgo), el ordenamiento jurídico no tiene lagunas. De acuerdo con Sosa Wagner (2005), este autor "pretende limpiar la jurisprudencia de todos aquellos elementos valorativos procedentes de la historia, la ética, la filosofía o la política, [...] Laband no suele ir más allá de la explicación de los distintos preceptos legales o reglamentarios" (p. 161). Entre sus contradictores se encuentra Otto von Gierke, quien le criticaba la asepsia de su tesis, en la medida en que quería explicar el Estado y su funcionamiento.

En el caso de Georg Jellinek (1851-1911) se distancia de Paul Laband en cuanto al apartamiento de las consideraciones políticas, históricas y filosóficas del derecho (Sosa Wagner, 2005). Para él, el Estado "ha de hacer la afirmación de su propia existencia, de la seguridad y el desarrollo de su poder, establecer el derecho y ampararlo, y favorecer a la cultura, problemas que solo a él corresponden" (Jellinek, 2002, p. 261). Ese autor le dice adiós al positivismo que comprendía Laband e incorpora la contemplación social del Estado. Tal como señala Sosa Wagner (2005):

distingue entre la parte normativa y la empírica del Estado, pero ambas deben contemplarse como fenómenos de la conciencia del hombre [...]. Su distinción entre una teoría general social del Estado y una teoría general jurídica del Estado, que permite tener en cuenta las ciencias sociales empíricas y, al tiempo, asegurar la provincia autónoma de lo jurídico, del derecho [...] la parte social descansa en el fundamento de las propias relaciones humanas, la jurídica en la idea del Estado como un sujeto de derecho, como una corporación territorial del Derecho público (territorio, pueblo y poder) (p. 197).

Además, se refiere al rol del Estado en relación con las relaciones con la sociedad:

la actividad específica de los médicos, profesores, maestros, ingenieros, funcionares del Estado, es individual, y no puede menos de serlo. El Estado autoriza su acción, pero jamás es esta el contenido de un órgano del Estado, porque este es el modo, peculiar de determinar el exterior aquellas actividades. Solo puede ordenar que se lleven a cabo tales actividades según determinados principios, y que se siga de ellas determinados efectos. Puede mandar la cantidad, pero no la calidad del servicio (Jellinek, 2002, p. 258).

Por otra parte, Otto Mayer (1846-1924) comprende el poder estatal y no la solidaridad como la característica principal del Estado de aquella época. De acuerdo con Bullinger (2005), "quien pretendía un servicio de una institución administrativa tenía que someterse a un régimen unilateralmente dictado, que carecía de base legal y así se integraba en una relación especial de sujeción" (p. 37).

Así las cosas, la administración intervenía en la sociedad de acuerdo con lo establecido en la ley, pues, como Estado liberal que era, su preocupación principal es el mantenimiento y el restablecimiento del orden público comprendido en sentido estricto. Entonces, "el objetivo primario de la policía administrativa ha venido siendo así la evitación y eliminación de peligros. El objetivo final, el restablecimiento del orden público perturbado [...]. Un estado ideal de peligro cero" (Esteve Pardo, 2003, p. 328).

Para lograr su cometido, la administración se apoyaba en instrumentos, principalmente, requeridos o anunciados al administrado de forma anterior a la realización de la actividad. Con esto nos referimos a autorizaciones, permisos, prohibiciones $u$ órdenes que, en caso de incumplimiento, podrían traer aparejada una sanción administrativa que son, sobre todo, herramientas preventivas y de control (Esteve Pardo, 2016). 


\section{Administración prestacional en el marco del Estado social y democrático de derecho ${ }^{1}$}

Los cuestionamientos al modelo predecesor hunden sus raíces en la mitad del siglo xIX, de modo que ponen en evidencia la incapacidad del modelo liberal para responder a las exigencias sociales y económicas de la población. En aquel momento, producto de la presencia de una nueva clase social, las demandas sociales de distintos grupos, la solicitud de representación en los debates de lo público, la urbanización de población ${ }^{2}$, las relaciones entre el Estado y la sociedad cambian drásticamente, de manera que van en doble vía, tal como lo afirma Esteve Pardo (2016): "No solo es que la sociedad se conecta a la estructura del Estado y lo sustenta. Se produce también y simultáneamente el movimiento de signo inverso: el Estado, que se sabe legitimado para ello, actúa ampliamente sobre la sociedad" (p. 51).

Estas intensas relaciones entre sociedad y Estado que se comienzan a tejer se evidencian de variadas formas, como los casos de la creación de más universidades, la implementación de medidas sanitarias para proteger a la población de las enfermedades, el intento de homogenizar los pesos y la medidas, la adopción de medidas positivas en materia de seguridad social, la limitación a los precios y a las horas de trabajo o el caso de la limitación de

1 "El alcance del ESDD, al amparo de lo regulado en la definición del Estado constitucional colombiano (Art. $1^{\circ}$ C.P.) se basa en cuatro principios esenciales, que delinean los aspectos estructurales de la función estatal de cara a los ciudadanos: la dignidad humana, el trabajo, la solidaridad y la igualdad" (Corte Constitucional, C-288/2012).

2 Se resalta cómo, a mediados del siglo XIX, los conglomerados humanos comienzan a crecer y con ello la necesidad de responder a las demandas propias de la vida urbana. Los alemanes se apoyan en la figura de la policía administrativa (policía de seguridad) para intervenir, y los franceses, españoles e italianos en la figura del dominio público, que luego quedaría comprendida en la figura de servicio público. los monopolios 3 . Tal como lo señala García Pelayo, "en todos los países se establecieron medidas arancelarias destinadas a defender ramas económicas específicas de la competencia exterior, al menos [...] hasta que estuvieran en disposición de enfrentarla por sí sola" (p. 19).

De esta manera, el Estado, a través de su aparato administrativo, cumple con sus cometidos al dirigir la economía, prestar los servicios básicos, construir la infraestructura y dirigir las reformas de modernización (Esteve Pardo, 2015). La administración del Estado no se encarga solo de mantener el orden público, sino de atender un abanico más grande de necesidades de la población, tales como la educación, la salud, la seguridad social, el transporte, el trabajo y la vivienda, entre otros: "Habiéndose desplazado como tema central político, el problema de la libertad, para ser sustituido por el problema de la seguridad social" (Garrido Falla, Palomar Olmeda y Losada González, 2005, p. 83). Para esto, el Estado fortalece su institucionalidad y aumenta el número de personas a su servicio. De esta manera, supera el modelo liberal, propio del siglo xix, y se centra en la actividad de prestación de servicios públicos. Tanto así que lo consideraron como el atributo esencial del Estado, en vez de la soberanía o del poder.

En este nuevo rol, el Estado, por intermedio de su administración, asume la calidad de empresario, productor de bienes y servicios, bien sea por "razones estratégicas, [...] para salvar y reflotar empresas en crisis, o para suplir las carencias de la iniciativa privada" (Sánchez Morón, 2006, p. 53). De manera que recae el coste de esta nueva interrelación entre Estado y sociedad en el sistema fiscal y tributario, "que se concibe como un sistema de compensación y corrección de los desequilibrios económicos de la sociedad" (Esteve Pardo, 2016, p. 51).

Son varios los autores que contribuyeron a la construcción de las teorías que sustentan el nuevo

3 Para el caso colombiano, resulta interesante el artículo "Los albores del Estado social de derecho colombiano”, escrito por Laura Acosta Zarate y Ricardo Medina Rico, en el cual se realiza un recuento de la inclusión de lo social en las constituciones nacionales previas a la de 1991. 
rol que debe asumir la administración para responder a las exigencias de la sociedad. Entre otros, se encuentran Lorenz von Stein, Hauriou y Duguit, Heller o Forsthoff.

Lorenz Von Stein (1815-1890) se refiere al rol de la administración en relación con la sociedad, en tanto que le solicita que genere condiciones necesarias económicas y sociales que las personas no pudieran crearse por su cuenta. Está convencido de que la administración tendrá un rol más activo en relación con la sociedad misma. Además, para esto se debe crear un nuevo derecho administrativo más cercano a las necesidades de la sociedad. Subraya "la importancia de la contemplación de la administración como algo más que el objeto del desnudo tratamiento jurídico" (Sosa Wagner, 2005, p. 130).

Para Maurice Hauriou (1856-1929), "la misión de la administración no es, exclusivamente, la de ejecución de la ley correspondiéndole también la de graduar y dar vida a las instituciones" (Alli Aranguren, 2001, p. 12). Este autor sitúa en el centro de esta disciplina al poder público, el que se concibe "como un poder de dominación dirigido a garantizar el orden y la estabilidad, condiciones necesarias para el desarrollo y la armonía social" (Rodríguez-Arana Muñoz, 2013, pp. 61-100). De esta manera, según este autor, el poder político, "posee medios eficaces para combatir el capitalismo por su legislación y por sus instituciones [...]. A condición de saber utilizarlo, el poder político parece muy capaz de remediar los inconvenientes de la libertad económica, sin necesidad de sacrificar esta" (Hauriou, 2003, p. 182).

En Francia, los cambios hacia una administración prestacional, entendida a partir de la categoría jurídica de los servicios públicos, irrumpe en el significado y el alcance de las relaciones entre el Estado/administración y la sociedad: "Es un compromiso político nuevo de los gobernantes en favor de la vertebración social del Estado y del interés general" (Troconso Reigada, 1999, p. 99). Así, aparece la teoría de los servicios públicos en Francia, con León Duguit (1859-1928) como uno de sus más importantes representantes. De esta manera, de acuerdo con Rodríguez-Arana Muñoz (2013), la solidaridad social es la "auténtica piedra angular de todas y la teoría sobre el servicio público, convirtió a Duguit en un adelantado a su tiempo" (p. 63); es, así, el servicio público la razón de ser del poder público. Además de ser esta institución la "fuente de legitimidad del derecho público y de las potestades y privilegios de la administración" (Esteve Pardo, 2016, p. 427). Se desplaza, entonces, el concepto de soberanía por el de servicio público como núcleo duro del derecho público (Esteve Pardo, 2013).

Por otra parte, Herman Heller (1891-1933) comprende que el Estado de derecho está fundado sobre contenidos materiales y éticos, de modo que para explicarlo era necesario hacerlo desde una perspectiva sociológica (Sosa Wagner, 2005, p. 596). Como lo explica García Pelayo:

la solución no está en renunciar al Estado de derecho, sino en dar a este un contenido económico y social, realizar dentro de su marco un nuevo orden laboral y de distribución de bienes: solo el Estado social de derecho puede ser una alternativa válida frente a la anarquía económica y frente a la dictadura fascista y, por tanto, solo él puede ser la vía política para salvar los valores de la civilización (García Pelayo, 2009, p. 17).

En el caso de Forsthoff (1902-1974), "introduce el concepto fundamental de procura existencial. A este concepto se conectaban todas las prestaciones que el Estado garantizaba a su comunidad nacional" (Masucci, 2011, p. 20). Debe así la administración preocuparse de asegurar las condiciones de vida de las personas, y realzar la idea de prestación "por encima de la tradicional intervención de la doctrina clásica ya claramente insuficiente para explicar el muy variado protagonismo de la administración" (Sosa Wagner, 2005, p. 582).

De este modo, la dogmática del derecho administrativo se transforma en una que tenía una administración prestadora de "servicios a los ciudadanos e intervencionista sobre sus actuaciones" (Alli Aranguren, 2001, p. 211). Así se hizo responsable de las prestaciones existenciales al Estado, consecuencia esto de su preocupación por la debilidad del Estado "frente a los grupos organizados, de ahí que se preguntará en más de una ocasión: ¿Quién garantiza el interés general?" (Bullinger, 2005, p. 34). 
En cuanto a la implementación de este nuevo modelo, se comenta en términos generales que los cambios administrativos son mucho más ágiles que los constituyentes, lo cual llevó a que el legislador acuñara en Francia la figura de los servicios públicos en el siglo xix con Hauriou y Duguit, y el Consejo de Estado francés, a partir de la decisión de Blanco (1873).

Tocará esperar hasta después de la Segunda Guerra Mundial para consolidar de pleno derecho en Europa occidental el modelo de Estado social y democrático de derecho, sin desconocer los avances en las constituciones de Querétaro, 1917, y Weimar, 1919. Al comprender esta forma de Estado una "función del orden constitucional de carácter jurídico y social, de naturaleza estabilizadora, que pretende fundamentalmente compensar las desigualdades sociales o estabilizar el Estado a partir de la nivelación de la sociedad" (Santofimio, 2009, p. 34).

Para lograr este objetivo, el Estado se sustenta en una administración prestacional; se pasa de la relación de súbdito a la de ciudadano, de las relaciones imperativas de la administración, a medidas que se dan en el plano del intercambio y la colaboración, sin perder las prerrogativas propias de la administración situadas en el plano del intercambio y la colaboración (Muñoz Machado, 2011).

En el caso de Alemania, luego de la Segunda Guerra Mundial se realizan grandes cambios no solo desde lo institucional, sino desde la cultura del derecho público. Así, se pasa de una sociedad de organización a una sociedad de individuos; ya el derecho público no es un derecho de la organización pública, sino uno que reconoce a los ciudadanos derechos públicos y garantías jurisdiccionales frente al poder público. Tanto así que si alguien resulta lesionado en sus derechos puede acudir al juez (Masucci, 2011).

4 En España, en la década de los cincuenta del siglo $\mathrm{xx}$, se inician cambios en la administración, de modo que se convierte, desde su nacimiento, en el primero y más poderoso foco de modernización. Asimismo, se dicta un número de leyes en temas administrativos, como es el caso de la expropiación forzosa, el procedimiento administrativo, la
Con esta intervención del Estado en la economía y en los aspectos sociales, la línea fronteriza entre sociedad y Estado, la cual se encontraba claramente diferenciada en el Estado liberal, se borra, lo que genera una serie de relaciones estrechas e imbricadas en las que, como lo señala Alli Aranguren (2001), la sociedad al perder su capacidad de autorregulación necesita del Estado y de su administración para la acción reguladora de la que carecía.

Así, la administración entra a desempeñar una serie de actividades desconocidas hasta entonces, denominadas: inspección, vigilancia, sanción, planeación, ordenación y servicios públicos. Además, sobre todo existe una relación marcada por un "Estado dominador y dirigente, por un lado, y una sociedad pasiva objeto de su acción, por otro, parece haberse invertido en sus dos términos" (Muñoz Machado, 2011, p. 200). En este sentido, se propone la división de las actividades de la administración en policía administrativa, servicios públicos y fomento. La policía englobaría todas las decisiones administrativas de limitación de derechos; a su vez, el servicio público son todas las prestaciones para los ciudadanos y mejorar sus condiciones de vida, así como la actividad de fomento busca estimular a los ciudadanos para cumplir con sus deberes. Entre los instrumentos empleados por la administración se cuentan no solo las autorizaciones, las prohibiciones y las órdenes, sino también las becas, los subsidios o las exenciones, además de las distintas clases de medidas prestacionales para el logro de los fines sociales del Estado.

Esta prestación de servicios y realización de distintas actividades conllevaría a que la institucionalidad del Estado creciera y se fortaleciera, lo que permitió a las entidades del Estado cumplir aquellas actividades que otrora estaban en cabeza de los particulares, con lo cual se borra la "frontera

administración del Estado y la jurisdicción contenciosa, lo que permitió dar un giro liberal al sistema autoritario que se vivía. En el campo estructural, se dicta la ley de funcionarios civiles, la ley de retribuciones, que "renacionalizó la función pública española y puso fin a un sistema de signo claramente feudal" (Fernández, 2001, pp. 11-12). 
entre Estado y sociedad, entre Estado y mercado" (Esteve Pardo, 2003, p. 59).

A lo anterior se agrega que este modelo, al modelo de Estado social, integra el carácter de democrático,

la participación social se presenta como una condición inexcusable para el diseño, implementación y evaluación de las políticas públicas y a la caracterización social del Estado se agrega su condición democrática, [...] Atrás quedaron las versiones cerradas y unilaterales del interés general, abriéndose las puertas a nuevas perspectivas que han de contar con la presencia y participación de los ciudadanos. Es decir, el interés general ya no se define unilateral y monopolísticamente por la administración pública, como antaño. Ahora es preciso convocar y recibir la vitalidad real que emerge de la vida social, lo que reclama una cada vez más intensa y honda participación social ${ }^{5}$ (Rodríguez Arana Muñoz, 2017, p. 97).

\section{Administración reguladora en el marco del Estado garante}

El rol activo del Estado en el proceso económico tambalea como consecuencia de la globalización (Chevallier, 2011), la crisis económica, la sociedad del conocimiento, la crisis ambiental, las actividades riesgosas y eminentemente técnicas en aumento en nuestra sociedad, la crisis de representación, las ideas neoliberales dominantes a finales del siglo xx (Sánchez Morón, 2006), y la huida del derecho administrativo, causas todas ellas que obligaron al Estado a adoptar otras formas de intervención distintas a las propias del Estado prestacional. En el

5 "En este contexto, la constitución sustituye a la legalidad administrativa como la principal fuente del derecho y comienza tímidamente un proceso en el que la administración pública, más allá de esa legalidad administrativa, positiva o negativa, se compromete con la realización de los valores y objetivos constitucionales, especialmente de los postulados del Estado social y democrático de derecho en la cotidianeidad a través, sobre todo, de la acción del complejo gobierno-administración pública” (Rodríguez Arana-Muñoz, 2017, p. 97). caso europeo, tal como afirma Cantero Martínez (2011), se anota también la influencia de las políticas de la Unión Europea que aceleraron este proceso, en la medida en que esta organización se ha edificado sobre la base de una economía de "mercado abierta y de libre competencia”, lo cual pone, según Troconso Reigada (1999), en tela de juicio la actividad del servicio público.

En lo que corresponde a la gestión de los nuevos riesgos que se dan en una sociedad industrializada, el rol de la administración evoluciona, pues pasa del interés de neutralizarlos o, en su defecto, suprimir el peligro, a gestionar el riesgo, y esto en tanto no es posible eliminar el peligro de forma total, de modo que debe la sociedad ser consciente y decidir sobre el tipo de riesgo que asume (Esteve Pardo, 2003).

El cuestionamiento al impacto de las medidas sociales por el Estado criticó su costo, la limitación a las libertades individuales y el rol pasivo de un sector de la sociedad que se acostumbra a vivir del Estado (Chevallier, 2011).

En cuanto a las ideas neoliberales tenían por objetivo frenar los efectos del Estado prestacional en Inglaterra y Estados Unidos, en procura de parar el crecimiento estatal. Estas políticas fueron adoptadas por Margaret Thatcher y Ronald Reagan, "para quien[es] las intervenciones y reglamentaciones gubernamentales exageradas, desordenadas e ineficaces son la fuente de todos los males de los que sufre la sociedad estadounidense" (Chevallier, 2011, p. 104). En Gran Bretaña, este proceso tiene lugar en 1979, y en los países en vía de desarrollo hacia la década de los noventa.

Todos estos supuestos tuvieron impacto en el escenario al generar la "recomposición en profundidad de las relaciones entre Estado y sociedad" (Esteve Pardo, 2015, p. 22), desde hace dos décadas. Esto, en la medida en que, en los últimos años, se trasladó buena parte de los servicios de interés general al mercado, "reemplazando la prestación pública por la combinación de regulación e intervención sobre la prestación privada en competencia” (Vaquer Caballería, 2013, p. 26).

En este caso, el Estado y su administración dan un paso atrás, lo cual permite que la iniciativa privada tenga el protagonismo de lo que otrora 
se ocupaba el Estado, con la consecuencia de que la administración no "modela ni petrifica la iniciativa privada o los criterios de racionalización a los que esta se sujeta, sino que respeta su propia dinámica de funcionamiento" (Schmidt-Abmann, 2006, p. 99).

Así, el rol de esta nueva administración es garantizar que en la "gestión y actuación del sector privado se atiendan los intereses generales comprometidos y se alcanzan los objetivos y requerimientos que marcan la constitución y las leyes" (Esteve Pardo, 2015, p. 20). Su finalidad, entonces, no es prestar el servicio como antaño hacia el Estado y la administración prestacional, sino más bien la administración garantiza que quien realiza la actividad lo haga en debida forma, de manera que garantiza el resultado final (Schmidt-Abmann, 2006). En este sentido, afirma Esteve Pardo (2015), "el Estado garante tiene así un carácter exclusivamente instrumental: no es un fin en sí mismo, sino que pretende ser otro modo y otro medio de realización del Estado social y de cumplir con sus objetivos" (p. 21). Por tanto, el Estado no es más el eje sobre el que se desarrolla el proceso económico, sino que más bien cumple funciones arbitrales del juego económico, "limitándose a encuadrar el juego de los operadores y esforzándose en armonizar sus acciones" (Chevallier, 2011, p. 109).

De esta forma, se pasa de una actividad de servicios públicos a cargo del Estado a unos servicios de interés económico-general realizados por particulares, pero regulados por el Estado:

es así como han aparecido servicios de interés económico general que no son servicios públicos; y un régimen peculiar de los servicios de interés económico general que no es el de los servicios públicos. Un régimen que también comporta matizaciones a la pura aplicación de las reglas del mercado libre y de la competencia, pero matizaciones menos drásticas que las de los prototípicos servicios públicos. Un régimen que es una especie de híbrido en el que ya no se utilizan las formas clásicas del servicio público (por gestión directa o indirecta) pero no se renuncia a las aspiraciones prototípicas de los servicios públicos: garantizar a todos ciertas prestaciones básicas y, así, lograr cierto grado de cohesión social y territorial (Rebollo Puig, 2018).
En el caso de ciertas actividades realizadas por la administración, se trasladaron, en algunas ocasiones, a los particulares las funciones de autorización, inspección y certificación en distintos sectores, aprovechando su conocimiento técnico. Se apoya la administración en el conocimiento técnico de los particulares para el ejercicio de sus funciones administrativas (Cantero Martínez, 2011).

Esta nueva actividad de la administración tiene su núcleo duro en la satisfacción de las necesidades básicas que se desarrollan en régimen de competencia y realizan los particulares (Troconso Reigada, 1999). Ahora bien, estos particulares no pueden cumplir la actividad de cualquier manera, por el contrario, están vinculados por una serie de obligaciones tales como "universalidad del servicio, su continuidad, calidad del servicio, horarios, gestión autónoma al margen de otros negocios de la empresa" (Troconso Reigada, 1999, p. 135). Demandas que exigen, en tanto los particulares que prestan dichos servicios ostentan una posición de poder frente al resto de la sociedad, el control de su actividad por parte de la administración (Esteve Pardo, 2016, p. 53).

De otra parte, Schmidt-Abmann (2012) comenta que estas nuevas relaciones entre el Estado y la sociedad ya no se pueden concebir como antaño a partir de los poderes públicos y sus teorías residuales, sino, por el contrario, por una ciencia de dirección: "Esto es como una ciencia que aspira a dirigir con eficacia los procesos sociales. Esto implica una cierta distancia e innovación respecto del pensamiento jurídico-administrativo tradicional en lo que a su concepción dogmática y metodológica se refiere" (Schmidt-Abmann, 2012, p. 44).

Asimismo, las transformaciones comentadas a finales del siglo xx y comienzos del actual tienen su reflejo en la actividad de la administración, pues resulta poco viable encuadrarlas en las categorías tradicionales de policía, fomento y servicios públicos (Ramírez Torrado y Hernández Meza, 2018). Con esto se generan dos planteamientos: "La doctrina del derecho administrativo del Estado como garante y el derecho administrativo de la regulación" (Wahl, 2013, p. 133).

Ahora bien, la administración garante se da en el marco del Estado social y democrático de 
derecho, pues, como lo advierte la doctrina, lo que se ha modificado es la actividad que cumple la administración y no la finalidad del Estado mismo, ya que el gran inconveniente es la sostenibilidad del modelo. De esta manera, lo que demanda el Estado social es que se garanticen unas prestaciones, pero no exige de ninguna manera que sea el mismo Estado el que las realice (Troconso Reigada, 1999): "Se plantean, sí, reformas parciales, pero no hay un modelo que se defina de manera ordenada y sistemática como alternativa o evolución del Estado social a diferencia de lo que este fue respecto a modelos que sustituyó o perfeccionó" (Esteve Pardo, 2015, p. 14).

Este cambio en las funciones de la administración genera un impacto en los instrumentos que emplean y, por ende, en el derecho administrativo, debiendo "adaptar su instrumentarium para explicar, en el plano dogmático las variadas manifestaciones del ejercicio de tales funciones" (Carro Fernández-Valmayor, 2014, p. 35). Entonces, se pasa de unos instrumentos clásicos de la administración fuertes e impositivos para controlar los fenómenos sociales y económicos, concretados principalmente en la relación ley/reglamento, a una "nueva modalidad interventora la light intervention, multilateral y dialógica, que se basa en el binomio ley-regulación" (De Figueiredo Moreira Neto, 2012, p.). Esto permite la participación de los diferentes sectores de la sociedad involucrados en la toma de decisiones. Así, en "amplios sectores la intervención pública que se canalizaba a través de la autorización al ser desplazada por el régimen de comunicación o declaración responsable que entrega a sí a la sociedad, a los particulares, el establecimiento de fórmulas de cobertura" (Esteve Pardo, 2015, p. 18).

Si bien se flexibiliza la otrora relación ley/reglamento, esto no quiere decir que las relaciones se den por fuera del derecho; en este sentido, la doctrina se ha manifestado al afirmar que estas relaciones las cumplan la administración, los particulares o de forma mixta, y que se transita del principio de legalidad al de juridicidad (De Figueiredo Moreira Neto, 2012).

Otro impacto en los instrumentos de la administración garante es el tipo de instrumento típico empleado por la administración que pasa de realizar un control preventivo (autorizaciones, permisos) a un control ex post, lo que se va a evidenciar con actividades relacionadas con la inspección, la vigilancia y la sanción. Además, se justificarían los controles previos, "ya que el objetivo perseguido no pueda conseguirse mediante una medida menos restrictiva, en concreto porque con control a posteriori, se produciría demasiado tarde para ser eficaz" (Alonso Sánchez, 2013, p. 63). De este modo, tal como lo pone de manifiesto Descalzo González (2012), los instrumentos de la administración, surgidos en momentos distintos, lejos de excluirse unos con otros se aplican en su conjunto de acuerdo con la necesidad de la administración.

Por último, se pueden citar como rasgos de las instituciones que realizan la actividad reguladora en la administración garante los siguientes:

- Las administraciones independientes. Son un rasgo de este rol de la administración. Esta es una independencia que implica no recibir instrucciones en el ejercicio de sus competencias. Cuando son funciones que se comparten con el Gobierno, el rol del ente regulador debe estar previamente definido (Hubert, 2004). Estos entes reguladores en los distintos países son autónomos del Ejecutivo, aunque existen algunos que, de alguna manera, se encuentran vinculados al Ejecutivo. Con la autonomía, lo que se intenta es neutralizar políticamente la realización de determinadas funciones que deben quedar por fuera de los intereses partidistas (Carlón Ruíz, 1999). Sin embargo, la autonomía de estos organismos la critican algunos sectores de la doctrina, tal como lo evidencia García Álvarez (2006), en razón esto al temor a que configure un Estado neutral, o bien por el riesgo de que "este tipo de entes, pequeños y muy especializados, sean en la práctica más permeables a las presiones de los agentes económicos dominantes en cada sector". (p. 144).

- Actividades que se regulan. Regulación de la economía (servicios económicos de interés general), regulación de riesgos y protección de derechos fundamentales (Esteve Pardo, 2016). La dirección de estos órganos está a cargo de los presididos por órganos colegiados (García Álvarez, 2006). 
- En qué consiste la actividad de regular. Por una parte, persigue garantizar a distintos niveles la existencia de mecanismos de competencia entre operadores para corregir los fallos del mercado, $y$, por otra, cumple el objetivo de cumplir con las exigencias derivadas de los intereses generales (Carro Fernández-Valmayor, 2014).

- Potestad normativa. La de estos entes para dictar normas con carácter imperativo y en otras ocasiones dicta recomendaciones que no son jurídicamente vinculantes (Muñoz Machado, 2011). Regulan tanto a particulares como a entidades del Estado que realizan actividades susceptibles de ser reguladas.

- Naturaleza de las normas que dictan. En cuanto a las decisiones de los entes reguladores, no tienen las mismas características de los actos administrativos que tienen un encuadramiento muy estricto a la ley y en los que la discrecionalidad está controlada. En este caso, existe un margen de discrecionalidad económica y técnica, de modo que permite a la autoridad tener límites más flexibles a la hora de tomar las decisiones (Ariño Ortiz, 2010). A esto se suma que las disposiciones normativas las realiza un personal en muchos casos no jurista, lo cual es denunciado por la doctrina, así las normas se realizan sin pasar por filtros que se contrastan con la realidad jurídica (García Álvarez, 2006). Por tanto, se puede decir que su actuación no implica la ejecución de la ley, como acontece normalmente en el derecho administrativo.

- Otorgamiento de títulos habilitantes. Algunas de estas entidades, de acuerdo con su campo de acción, entregan autorizaciones a los particulares para realizar una actividad (Carlón Ruiz, 1999).

- Potestad sancionadora. En tanto cumple funciones administrativas por la violación a los bienes jurídicos protegidos por ese sector.

- Se encargan de resolver conflictos entre particulares. A partir de la determinación del contenido o ejercicio de los derechos, de acuerdo con Muñoz Machado (2011). El autor menciona que "los conflictos no se plantan ya entre un servicio público y sus usuarios, sino entre empresas que desarrollan una actividad en régimen de competencia en el mercado y los particulares que utilizan sus servicios" (p. 226). En el caso español esta función ha aparecido en la sectores liberalizados en temas de telecomunicaciones y del sector eléctrico. Las decisiones son controlables finalmente por los jueces.

\section{Conclusión}

Las relaciones Estado/administración han determinado el papel del derecho administrativo, y a su vez sus objetivos e instrumentos empleados. Pasan de una actividad reducida de la administración a un bajo número de instituciones estatales y al empleo de instrumentos de control administrativos de carácter previo; se apoyan para esto en teorías que desde diferentes perspectivas respaldan que las dinámicas entre el Estado y la sociedad residan en planos diferentes. De este escenario se transitó a otro modelo de Estado, en el cual los fines de este cambian de forma dramática, de manera que se permitió que se multiplicara la actividad, las instituciones y los instrumentos de la administración. Además, en el que el Estado y la sociedad conviven en el mismo círculo. Desde hace algunos años ya no se ha reacomodado, en esta ocasión, el modelo de Estado mismo, sino su administración. Se centra esta última en la regulación de las actividades a cargo de los particulares que, en la titularidad estatal de la actividad prestacional, encuentran un reflejo inevitable en el derecho administrativo de su actividad, de sus órganos e instrumentos.

\section{Referencias}

Alli Aranguren, J. C. (2001). El derecho administrativo y la evolución del Estado. Estudios de Deusto, 49(1), 171218.

Alonso Sánchez, I. (2013). La simplificación administrativa como política económica y su especial consideración en Castilla y Léón. En Nuevas formas de control de la adminitración pública y su repercusión sobre consumidores y usuarios (pp. 49-83). Salamanca: Ratio Legis.

Alviar García, H. (2007). Una mirada distinta a las transformaciones del derecho administrativo. Revista de Derecho Público, 2-14. 
Ariño Ortiz, G. (2010). El control judicial de las entidades reguladoras. La necesaria expansión del Estado de derecho. Revista de Administración Pública, 182, 9-37.

Braibant, G. (2002). Le passé et l'avenir de l'administration publique. Revue Francaise d'Administration Publique, 213-221.

Bullinger, M. (2005). El service public francés y la daseinsvorsorge en Alemania. Revista de Administración Pública, 166, 29-49.

Cantero Martínez, J. (2011). A vueltas con el ejercicio de potestades públicas y su ejercicio por los particulares. Nuevos retos para el derecho administrativo. Revista Española de Derecho Administrativo, 151, 627-649.

Carlón Ruiz, M. (1999). La comisión del mercado de las telecomunicaciones. Revista Española de Derecho Administrativo, 102, 229-255.

Carro Fernández-Valmayor, J. (2014). Reflexiones sobre las transformaciones actuales del derecho público, en especial del derecho administrativo. Revista de Administración Pública, 193, 11-44.

Chevallier, J. (2011). El Estado posmoderno (O. Pérez, Trad.). Bogotá: Universidad Externado.

Corte Constitucional. (2012), Sentencia C-288. M. P. Luis Ernesto Vargas Silva, 18 de abril.

Descalzo González, A. (2012). Organización y acción administrativa en la economía. En L. Parejo Alfonso, Lecciones de derecho administrativo. Valencia: Tirant lo Blanch.

Esteve Pardo, J. (2003). De la policía administrativa a la gestión de riesgos. Revista Española de Derecho Administrativo, 119, 323-346.

- - - . (2013). La nueva relación entre Estado y sociedad. Aproximación al transfodo de la crisis. Madrid: Marcial Pons.

- - - . (2015). La administración garante. Revista de Adminitración Pública, 197, 11-39.

- _- - (2016). Lecciones de derecho administrativo (6 ${ }^{\mathrm{a}}$ ed.). Madrid: Marcial Pons.

Fernández, T. (2001). La administración del Estado a lo largo del siglo xx. Revista Española de Derecho Administrativo, 109, 5-14.

Figueiredo Moreira Neto, D. de. (2012). Logros democráticos de la regulación. Revista Española de Derecho Administrativo, 155, 67-74, 155.

García Álvarez, G. (2006). Los poderes normativos de las administraciones independientes en el ámbito económico. Revista de Administración Pública, 171, 139-179.
García de Enterria, E. y Fernández, T. (2006). Curso de derecho administrativo. Madrid: Civitas.

Garrido Falla, F., Palomar Olmeda, A. y Losada González, H. (2005). Tratado de derecho administrativo. Madrid: Tecnos.

García Pelayo, M. (2009). Las transformaciones del Estado contemporáneo. Madrid: Alianza.

Hauriou, M. (2003). Principios de derecho público y constitucional. Granada: Comares.

Hubert, J. (2004). Le cas de l'autorité de régulation des télécommunications. Revue Francaise d'Administration Publique, 99-107.

Jellinek, G. (2002). Teoría general del Estado. México: Efe.

Linde Paniagua, E. (2014). Las transformaciones del derecho público de nuestro tiempo. Madrid: Colex.

Martín-Retortillo Baquer, L. (2012). El derecho adminisrtativo ante la crisis. Revista Española de Derecho Administrativo, 157, 117-133.

Masucci, A. (2011). Formación y evolución del derecho administrativo en Francia y Alemania. Revista de Administración Pública, 184, 9-39.

Merkl, A. (2004). Teoría general del derecho administrativo. Granada: Comares.

Muñoz Machado, S. (2011). Hacia un nuevo derecho administrativo. En A. Blasco Esteve (ed.), El derecho público de la crisis economica. Transparencia y sector público. Hacia un nuevo derecho administrativo (pp. 191-237). Madrid: Inap.

Ramírez Torrado, M. L. y Hernández Meza, N. (2018). Análisis de las funciones administrativas y jurisdiccionales de la Superintendencia de Industria y Comercio en materia de libre competencia. Revista de Derecho del Estado, 41, 317-350.

Rebollo, Puig, M. y Jurado, D. J. (2018). Derecho administrativo. Tomo III: modos y medios de la actividad administrativa. Difusora Larousse. Editorial Tecnos.

Rodríguez-Arana Muñoz, J. (2013). Sobre las transformaciones del derecho público, de León Duguit. Revista de Administración Pública, 190, 61-100.

Sánchez Morón, M. (2006). Derecho administrativo. Parte general. Madrid: Tecnos.

Santofimio, J. (Diciembre de 2009). Carácter colectivo de las licencias urbanísticas bajo los presupuestos del Estado social y democrático de derecho. La ruptura del individualismo clásico en el procedimiento y decisión administrativa de licencia urbanística. Revista Digital de Derecho Administrativo. 2, 3-81. 
Schmidt-Abmann, E. (2006). Cuestiones fundamentales sobre la reforma de la teoría general del derecho administrativo. Necesidad de la innovación y presupuestos metodológicos. En J. Barnes (ed.), Innovación y reforma en el derecho administrativo (pp. 27-111). Sevilla: Inap.

Schmidt-Abmann, E. (2012). Cuestiones fundamentales sobre la reforma de la teoría general del derecho administrativo. En J. Barnes (ed.), Innovación y reforma en el derecho administrativo (pp. 21-140). Sevilla: Inap.

Sosa Wagner, F. (2005). Maestros alemanes del derecho público. Madrid: Marcial Pons.
Troconso Reigada, A. (1999). Dogmática administrativa y derecho constitucional: el caso del servicio público. Revista Española de Derecho Constitucional, 19(57), 87-164.

Vaquer Caballería, M. (2013). Del ғRов y los stress test: aportaciones de la crisis a la teoría sobre las formas de actividad de la administración. Revista Española de Derecho Administrativo, 157, 23-48.

Wahl, R. (2013). Los últimos cincuenta años de derecho administrativo alemán. Madrid: Marcial Pons. 